\title{
FORECASTING OIL SPILL DRIFT AT METEO-FRANCE
}

\author{
Pierre Daniel \\ METEO-FRANCE \\ SCEM/PREVI/MAR \\ 42 Avenue Coriolis \\ 31057 Toulouse, Cedex \\ France
}

\begin{abstract}
METEO-FRANCE developed an oil spill response system designed to simulate the transport of oil in three dimensions. This system is applicable anywhere in the world (with a coarser resolution far from the French coastlines) and is available around the clock. It was validated on a few well-documented pollution incidents, and it was tested twice in real time.

New developments, exercises, and training are conducted jointly with the collaboration of CEDRE (Centre de Documentation de Recherche et d'Expérimentation sur les pollutions accidentelles des eaux).
\end{abstract}

\section{Discussion}

In case of marine pollution by oil, METEO-FRANCE provides assistance to the marine pollution emergency response operations authorities. The intervention of METEO-FRANCE can be at a national level within the spill response plan POLMAR-MER in case of a threat to the French coastline, and it can be at an international level within the Marine Pollution Emergency Response Support System (MPERSS) for the high seas. The MPERSS is a World Meteorological Organization (WMO) system that has been implemented on an experimental basis since January 1, 1994. The purpose of this system is to provide meteorological support to marine pollution emergency response operations on the high seas. The oceans and seas are divided in areas of responsibility, and a national meteorological service is designated as area coordinator. METEO-FRANCE is the coordinator in area II and provides supporting service in areas I, III, and VII(B) (Figure 1). The support to emergency operations may include a variety of elements, such as basic meteorological forecasts and warnings for the area of concern; observation, analysis, and forecasting of the values of specific meteorological and oceanographic variables required as input to marine pollution models; operation of such models; and access to national and international telecommunication facilities.

Because of these engagements, METEO-FRANCE developed an oil spill response system. It consists of a two-dimensional ocean model linked to an oil spill model that includes shear current, vertical movements, and fate of the oil. The next section summarizes the key features of the model and then presents examples of model applications.

Key features of the model. Only a brief description is given in text following. More information can be found in Daniel (1995, 1996). A depth-integrated, limited area ocean model designed to simulate wind currents and tide currents is driven by the winds and sea level pressure forecasts from a global atmospheric model. This atmospheric model can be the European Center for Medium-Range Weather Forecasts (ECMWF) model or the METEO-FRANCE model (ARPEGE). In the English Channel and the Bay of Biscay, a tide forcing by 16 components is included in the model.

The oil slick is modeled as a distribution of independent droplets that move in response to shear current, turbulence, and buoyancy. This approach to following the movement of individual oil droplets has already been used in a number of oil spill models, but with a crude formulation of the shear current (Venkatesh, 1990; Proctor et al., 1994). Here, the shear current is calculated analytically for each droplet with a bilinear eddy viscosity model that assumes that the vertical eddy viscosity will increase linearly with the distance from both the water surface and the bottom boundary. The turbulence (diffusion) is represented by a three-dimensional random walk technique. The buoyancy force depends on the density and size of the oil droplets, so that larger (more buoyant) ones tend to remain in the surface layer, whereas the smaller droplets are mixed downwards. About $65 \%$ to $70 \%$ of the droplets remain on the sea surface. If a droplet is moved onto land, then that droplet is considered beached and takes no further part in the simulation.

The model was calibrated on a few well-documented pollution incidents, such as the Torrey Canyon, English Channel, 1967; the Amoco Cadiz, English Channel, 1978; the Tanio, English Channel, 1980; the Gulf War, Persian Gulf, 1991; and the Aegean Sea, La Coruna, Spain, 1992.

Real-time simulations. A marine weather forecaster on duty at the marine service in Toulouse can run the model on request. He provides oil spill position, time, duration of the release, and oil type (light crude oil, heavy crude oil, kerosene, gas oil, fuel oil, petrol). The model is then run for the required forecast period (typically 120 hours). The output is in the form of oil spill position charts. A 120hour forecast can be carried out on a Cray C98 computer in a few minutes. This system enables an investigation of a forecast scenario to be made in real time. The system has been operational since February 1994 and has already been used twice in real time.

On December 21, 1994, an accident occurred between Madeira and Cap de S. Vicente, Portugal. METEO-FRANCE ran the model from December 21, 1994, to January 6, 1995. Since METEO-FRANCE has responsibility for this area within the MPERSS, oil spill charts were sent to meteorological offices in Spain, Portugal, and Morocco, as well as to the oil company of the owner of the ship.

During the Sea Empress accident (February 1996, Wales), METEO-FRANCE was requested by CEDRE to send oil spill drift forecasts to them. Figure 2 shows an example of a 60 -hour forecast. Starting on February 22, 1996, at 12:00 GMT from an observed position of the slick, the simulation shows an eastern movement of the slick, which corresponded well with the observations.

Exercises. In association with CEDRE, the French Navy, and Saudi Petroleum Overseas Ltd., METEO-FRANCE took part in the exercise Antipol 95 (October 3-4, 1995). Antipol 95 was a simulation of an accident north of Batz island (Brittany, English Channel) with a tanker carrying 300,000 tons of light crude oil. A drifting buoy (NORDA type) simulated the oil slick drift. METEO- 


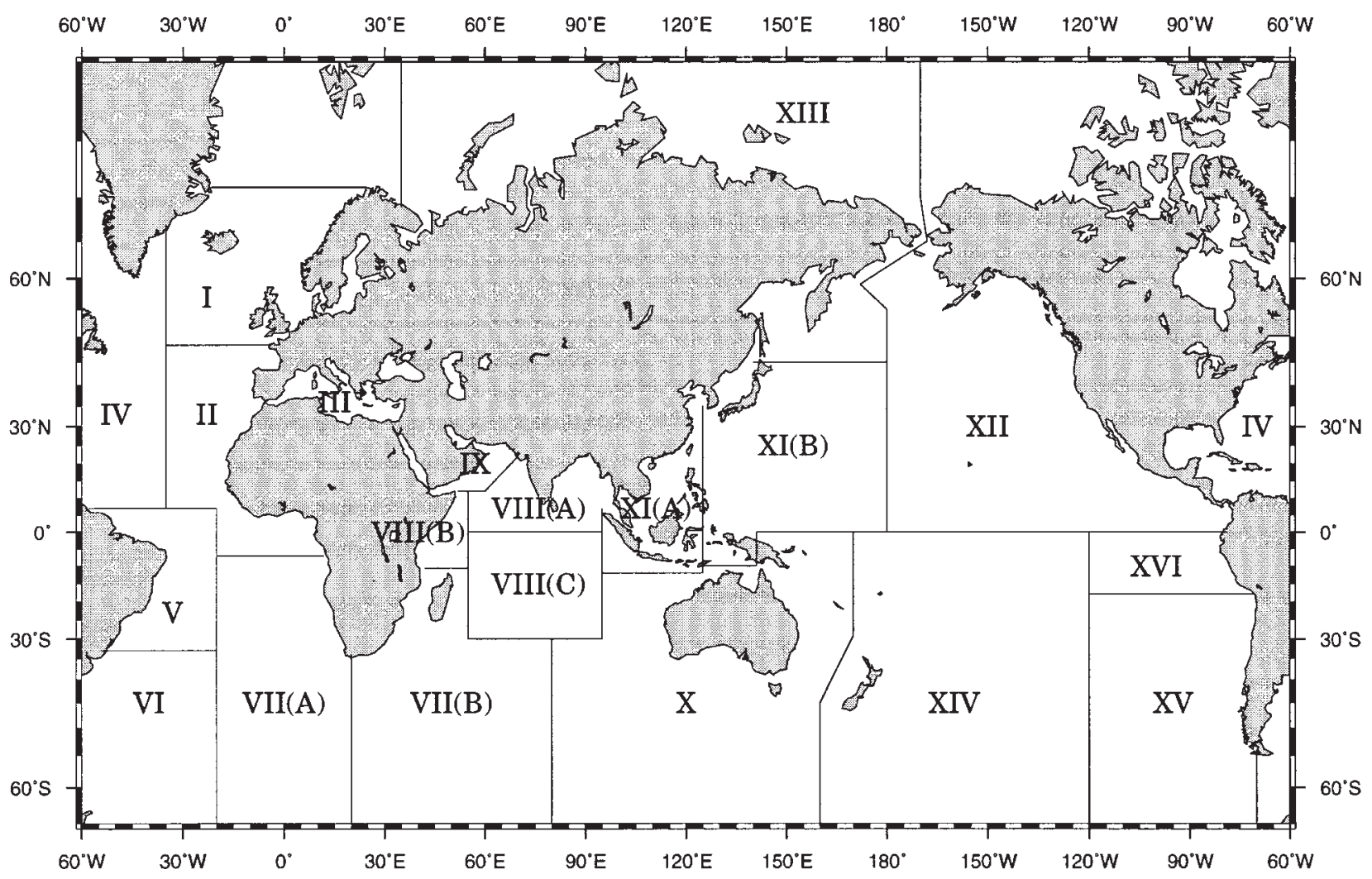

Figure 1. Marine Pollution Emergency Response Support System areas

FRANCE ran this model for 2 days and sent oil slick drift forecasts to CEDRE. Figure 3 summarizes a 2 -week model simulation. It shows the trajectories of the droplets and the buoy starting from the position of the accident. There is one position charted every 6 hours. Wind and atmospheric pressure were issued from the ARPEGE model. At the beginning, the winds were southwest, and the droplets moved exactly like the buoy. From October 9, the wind was very light, and the tide currents dispersed the slick. Most of the droplets moved slowly to the north; some of them moved to the southeast, passed south of Guernsey island, and then went to the north. The trajectory of these droplets is very similar to the trajectory of the buoy. It appears clear that the drift of a buoy cannot accurately represent the spreading of the slick.

\section{Conclusion}

The METEO-FRANCE oil spill model is able to accurately predict the transport of oil in three dimensions. The atmospheric forcing is provided in real time by a global atmospheric model. In some areas, improvements are necessary to increase the performance of the model.

Some processes, such as evaporation or emulsification, play a significant role during the drift of a slick. In collaboration with CEDRE, the inclusion of a weathering oil model is under study.

The ocean model is adapted for waters that are well mixed in depth, temperature, and salinity. For stratified seas such as the Mediterranean Sea, the model is less accurate. The use of a tridimensional hydrodynamic model that takes into account the effects of deep circulation is under study.

\section{Biography}

The author is in charge of oil spill drift modeling at METEOFRANCE. He is rapporteur on marine transport modeling within the World Meteorological Organization.

\section{References}

1. Daniel, P., 1995. Numerical simulation of the Aegean Sea oil spill. Proceedings of the 1995 International Oil Spill Conference. American Petroleum Institute, Washington, D.C., pp894-895

2. Daniel, P., 1996. Operational forecast of oil spill drift at METEOFRANCE. Spill Science and Technology Bulletin (in press)

3. Proctor, R., R. A. Flather, and A. J. Elliot, 1994. Modelling tides and surface drift in the Arabian Gulf: Application to the Gulf oil spill. Continental Shelf Research, v14, n5, pp531-545

4. Venkatesh, S., 1990. Model simulations of the drift and spread of the Exxon Valdez oil spill. Atmosphere-Ocean, v28, pp90-105 


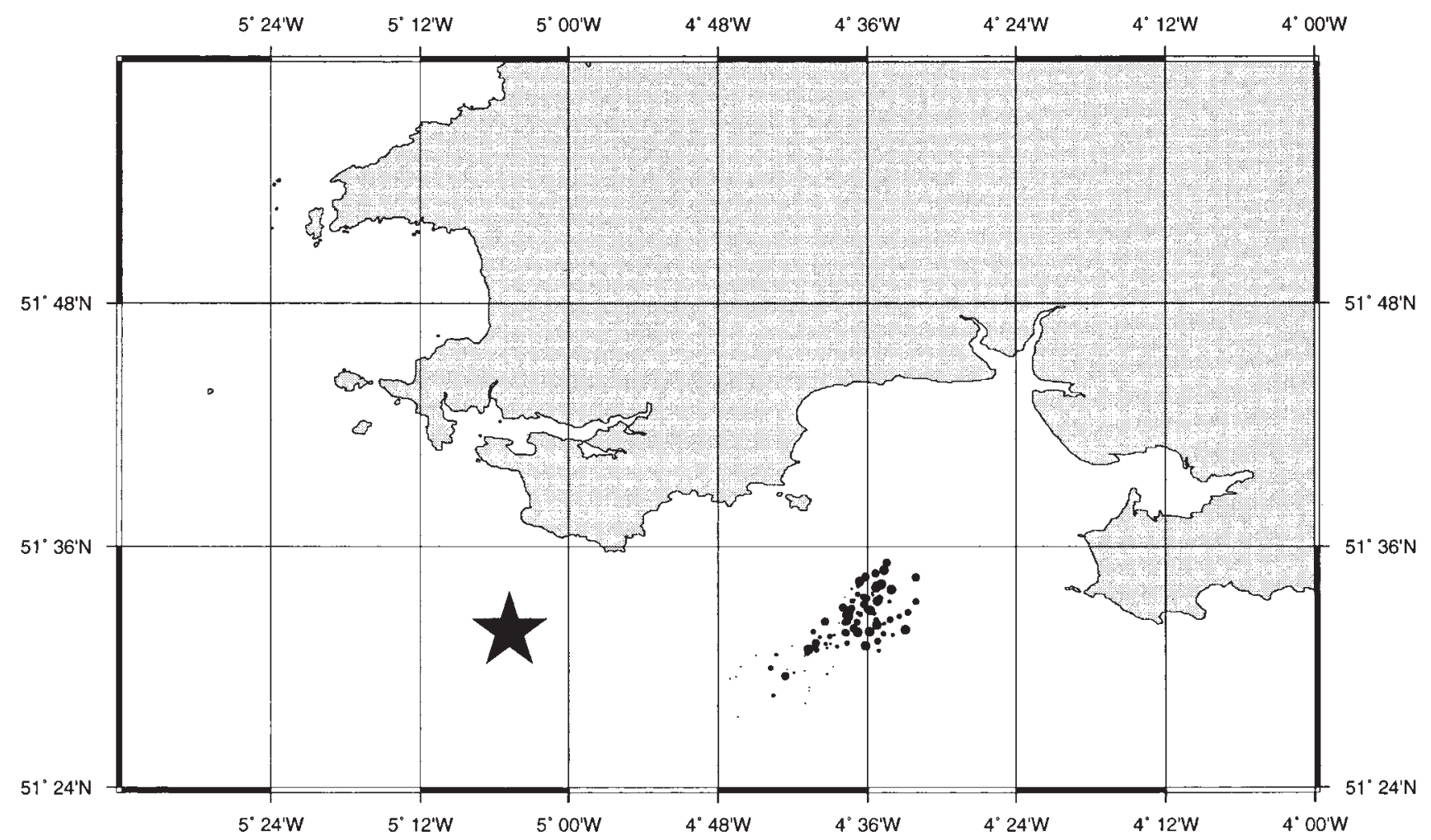

Figure 2. Sixty-hour forecast during the Sea Empress accident. The star indicates the starting position of the slick (February 22, 1996, at 12:00 GMT). The size of the droplets is related to their depth (the biggest are closer to the surface).

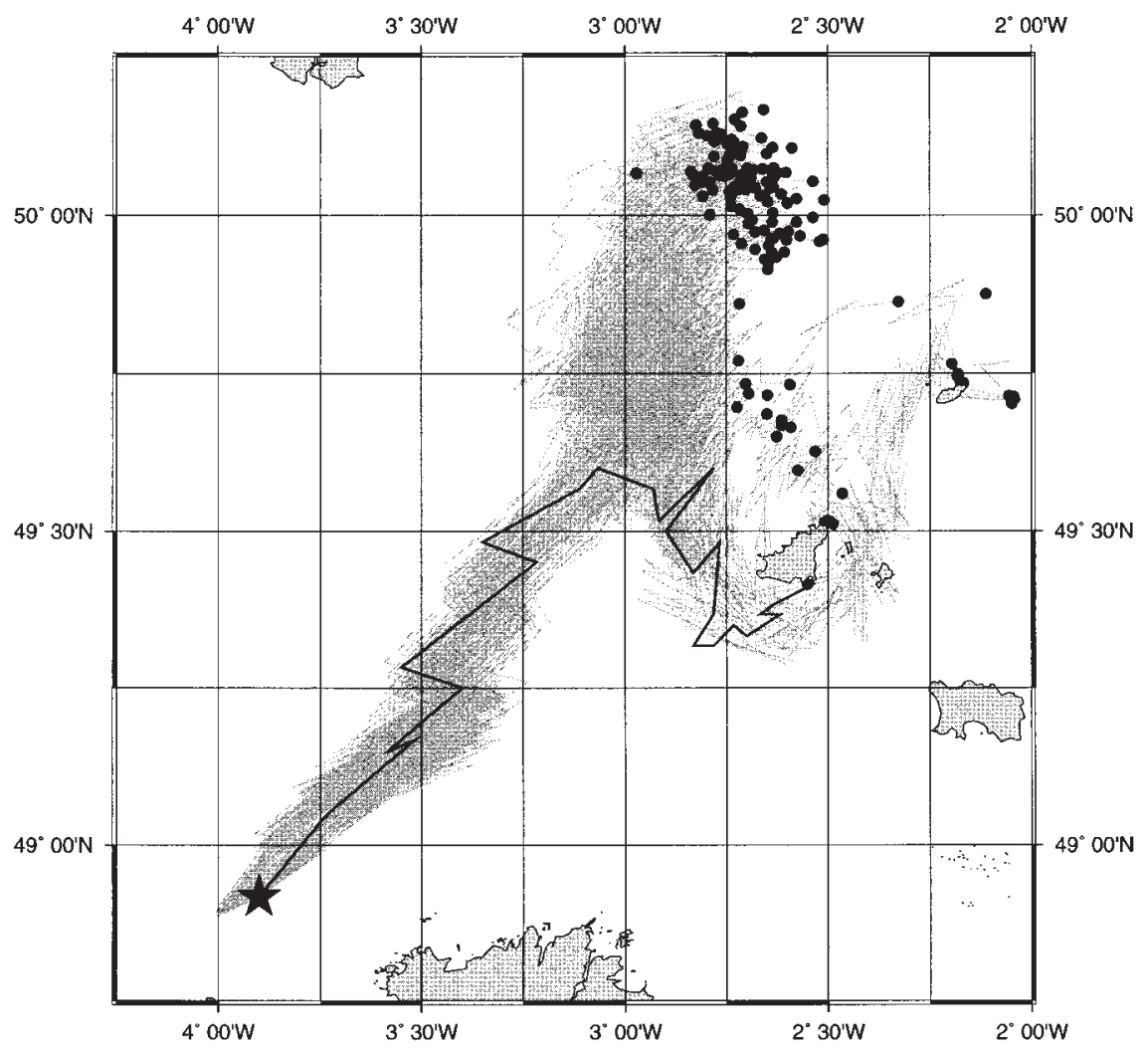

Figure 3. Trajectories of the droplets (gray) and the buoy (dark) during Antipol 95 (from October 3 to 17, 1995). The star indicates the starting position of both the slick and the buoy. The black disks indicate the final positions of the droplets. 